\title{
Organic contamination in the greenhouse soils from Beijing suburbs, China
}

\author{
L. L. Ma, S. G. Chu and X. B. Xu* \\ Research Center for Eco-Environmental Sciences, Chinese Academy of Sciences, Beijing \\ 100085, China. E-mail: xuxb@public.bta.net.cn; Fax: +86-10-62923563; Tel: +86-10- \\ 62919177
}

\author{
Received 27th May 2003, Accepted 22nd July 2003 \\ First published as an Advance Article on the web 5th August 2003
}

\begin{abstract}
Selected persistent organic pollutants including HCHs, DDTs and PAHs together with PAEs were determined in the greenhouse soils from Beijing suburbs. The total concentrations were $11.64-29.80 \mathrm{ng} \mathrm{g}^{-1} \mathrm{for}_{\mathrm{HCHs}}$, 18.04-101.33 $\mathrm{ng} \mathrm{g}^{-1}$ for DDTs, $1.34-3.15 \mu \mathrm{g} \mathrm{g}^{-1}$ for PAEs and 1.92-7.84 $\mu \mathrm{g} \mathrm{g}^{-1}$ for PAHs, respectively. Predominance of $\beta-\mathrm{HCH}$ in all samples was obviously observed, suggesting a lack of new HCHs sources. High concentrations of DDE and DDD in comparison to their parents in the samples indicated that most of the DDT had been transformed into its metabolites. The contamination of PAHs was relatively serious and the most abundant compounds were 4-, 5- and 6-ring unsubstituted PAHs. The profiles reflect the important effect of traffic on the PAHs remaining in greenhouse soils. Three phthalate esters (DIBP, DnBP and DEHP) accounted for more than $97 \%$ of the phthalates studied. Analysis of n-alkanes was also performed in order to trace the natural or anthropogenic sources of hydrocarbons. Characterization and identification of these compounds in greenhouse soil may help in development of strategies to be used in monitoring organic pollutants in this region.
\end{abstract}

\section{Introduction}

In recent years, persistent organic pollutants (POPs) such as some organochlorine pesticides (OCPs) and polycyclic aromatic hydrocarbons (PAHs) have attracted worldwide concern due to their hazards to the environment. ${ }^{1,2}$ In China, OCPs (mainly dichlorodiphenyltrichloroethane, DDTs and hexachlorocyclohexanes, $\mathrm{HCHs}$ ) used to be the most important pesticides, produced to enhance agricultural yields for more than three decades. A national survey in the 1980s showed the amount of OCPs occupied about $78 \%$ of all pesticide consumption during that period. ${ }^{3}$ Decades after being banned, they still could be found in the environment due to the persistence. ${ }^{4,5}$ PAHs are mainly generated from incomplete combustion or pyrolysis of organic material and some of them such as 4-ring to 6-ring PAHs exhibit carcinogenic and mutagenic properties. ${ }^{6,7}$ The US Environmental Protection Agency (EPA) has designated 16 unsubstituted PAHs (EPA$\mathrm{PAH}$ ) as priority pollutants. More recently, phthalic acid esters (PAEs), as a big group of man-made chemicals, are also of increasing concern although they are considered to be moderately persistent. ${ }^{8}$ Many studies have reported that phthalates have estrogenic effects and reproductive toxicity in animals. ${ }^{9-11}$ They are mainly used as plasticizers in the production of polymeric materials such as poly(vinyl chloride) (PVC). In China, PVC and other polymeric films are popularly applied as building materials in greenhouses used for planting vegetables.

Generally, the soil ecosystem seems to be the ultimate repository for many toxic chemicals. However, loss of organic pollutants from soil by evaporation or migration is a possible source of atmospheric and groundwater contamination ${ }^{12,13}$ and those remaining in soil could also reach adjacent vegetables and wildlife, ${ }^{14}$ thus causing direct or indirect exposure of humans to the organic pollutants. In fact, DDTs, HCHs, PAHs and PAEs are common contaminants found in the human diet, ${ }^{15}$ breast milk, ${ }^{16}$ blood $^{17}$ and urine samples. ${ }^{18}$ All these prompt us to take up the monitoring of such pollutants in the soil.
Beijing, as the capital with a population of 13819000 , is located in the north of China where vegetable production mainly depends on greenhouses especially in winter and spring. As far as we know, no research is available on the organic contamination in the greenhouse soils from Beijing suburbs where most of the vegetables are grown locally. The aim of this work is to explore the current pollution status of some selected POPs including DDTs, HCHs and PAHs together with PAEs in greenhouse soils, to investigate the previous and current possible inputs of the pollutants or to assess the sources of organic pollution.

\section{Experimental}

\section{Materials}

The standards of 16 EPA-PAHs and alkanes (from C13 to C35) each at $1000 \mu \mathrm{g} \mathrm{ml}^{-1}$ were purchased from Aldrich (WIS, USA). Two surrogates (2-flurobiphenyl and 2,4,5,6-tetrachloro- $m$-xylene) and six phthalate ester standards (dimethyl, diethyl, di-iso-butyl, di-n-butyl, di-(2-ethylhexyl) and di-noctyl phthalate, each at $1000 \mu \mathrm{g} \mathrm{ml}^{-1}$ ) were purchased from Supelco (Bellefonte, PA, USA). A composite stock standard solution of organochlorine pesticides at $100 \mu \mathrm{g} \mathrm{ml}^{-1}$ included $\alpha-, \beta-, \gamma-, \delta-\mathrm{HCH}, p, p^{\prime}$-DDE, $p, p^{\prime}$-DDD, $o, p^{\prime}$-DDT and $p, p^{\prime}-$ DDT (National Research Center for Certified Reference Materials of China). The standards were further diluted with isooctane to prepare working standards. All solvents were of analytical purity (Beijing Chemical Factory, China) and redistilled in all-glass system before use. Silica gel (100-200 mesh; Qingdao Haiyang Chemical Co. China) was activated at $130{ }^{\circ} \mathrm{C}$ for $12 \mathrm{~h}$. Florisil (60-100 mesh; Supelco.) was activated at $140{ }^{\circ} \mathrm{C}$ for $16 \mathrm{~h}$. Anhydrous sodium sulfate (Beijing Chemical Factory) was heated at $600{ }^{\circ} \mathrm{C}$ for $12 \mathrm{~h}$ to destroy the organic contamination. In order to avoid contamination during the experiment, glassware was prepared successively in the following order: washed with acetone and water, soaked in $5 \% \mathrm{~K}_{2} \mathrm{Cr}_{2} \mathrm{O}_{4}$ sulfuric acid solution overnight, washed with 
water and distilled water in turn, dried in an oven and rinsed with acetone just before use.

\section{Sampling and extraction}

Eight greenhouse samples, named $1 \#$ to $8 \#$, at different locations on the outskirts of Beijing were taken in April 2001. At each site, multiple cores were collected with a coring cylinder at an approximate depth of $5 \sim 20 \mathrm{~cm}$ to obtain one representative sample. Soil was air dried at room temperature, fully mixed, ground to 30 mesh and stored in glass bottles at $-4{ }^{\circ} \mathrm{C}$ until further processing. The remaining water content in the soil was determined gravimetrically after drying individual subsamples in an oven at $105{ }^{\circ} \mathrm{C}$ for $12 \mathrm{~h}$. All results were reported as dried weight.

Approximately $10 \mathrm{~g}$ of soil was homogenized with anhydrous sodium sulfate into free flowing powder, ultrasonically extracted in centrifuge tubes with $30 \mathrm{ml}$ of acetone-hexane $(1+1 \mathrm{v} / \mathrm{v})$ for $5 \mathrm{~min}$ and then the extract was separated by centrifugation. Such a process was repeated three times. The combined extract was divided into two portions, one for hydrocarbon analyses and the other for pesticides and phthalate ester analyses. Each portion was evaporated to $1 \mathrm{ml}$ in K-D apparatus under a gentle stream of nitrogen.

\section{Sample clean-up}

The portion for hydrocarbons was cleaned up with a chromatographic column $(30 \mathrm{~cm} \times 10 \mathrm{~mm} \mathrm{id})$ containing $10 \mathrm{~g}$ of silica gel with $1 \mathrm{~g}$ of anhydrous granular sodium on its top. The column was pre-eluted with $40 \mathrm{ml}$ of hexane before loading the sample. After the sample was transferred onto the column, it was eluted with $25 \mathrm{ml}$ of hexane and followed by $30 \mathrm{ml}$ of hexane-dichloromethane $(3+2 \mathrm{v} / \mathrm{v})$. The first fraction was n-alkanes and the second fraction was PAHs. The other portion was cleaned up with a chromatographic column containing $5 \mathrm{~g}$ of activated Florisil with $1 \mathrm{~g}$ of anhydrous sodium sulfate on the top. The first fraction containing OCPs was eluted by $50 \mathrm{ml}$ of hexane-diethyl ether $(90+10 \mathrm{v} / \mathrm{v})$. The second fraction containing phthalate esters was eluted with $50 \mathrm{ml}$ of hexane-diethyl ether $(40+60 \mathrm{v} / \mathrm{v})$. The solvent in each fraction was evaporated using K-D apparatus with a gentle stream of nitrogen, and then was adjusted to $0.2 \mathrm{ml}$ for analysis.

\section{Sample analysis}

Quantification of HCHs and DDTs was carried out on an Agilent 6890 gas chromatograph equipped with a ${ }^{63} \mathrm{Ni}$ electron capture detector (ECD). Separations were performed on a HP5 fused silica capillary column $(30 \mathrm{~m} \times 0.25 \mathrm{~mm}$ id, $0.25 \mu \mathrm{m}$ film thickness) with nitrogen as carrier and make-up gas. The GC oven temperature was programmed as follows: initial temperature of $100{ }^{\circ} \mathrm{C}$ was held for $2 \mathrm{~min}$, increased at a rate of $6{ }^{\circ} \mathrm{C} \mathrm{min}{ }^{-1}$ to $280{ }^{\circ} \mathrm{C}$, then held for $2 \mathrm{~min}$. The injector and detector temperature were $280{ }^{\circ} \mathrm{C}$ and $300^{\circ} \mathrm{C}$, respectively. $1 \mu \mathrm{l}$ of sample was injected in splitless analysis of PAEs, PAHs and alkanes was performed on an Agilent $6890 \mathrm{~N}$ equipped with DB-5 column $(30 \mathrm{~m} \times 0.25 \mathrm{~mm} \times 0.25 \mu \mathrm{m}$ film thickness $)$ and flame ionization detector (FID). Each temperature program was the same as follows: initial temperature of $50{ }^{\circ} \mathrm{C}$ was held for $2 \mathrm{~min}$, increased at a rate of $4{ }^{\circ} \mathrm{C} \mathrm{min}^{-1}$ to $280{ }^{\circ} \mathrm{C}$, then held for $20 \mathrm{~min}$. To confirm the results of OCPs, PAHs and PAEs, selected typical samples were checked with a Hewlett Parkard 6890 GC-5973MSD system. The GC-MS parameters were the same as described above except that the carrier gas was helium. The mass spectrometer was operated in full scan mode $(50$ $500 \mathrm{amu}$ ) for PAHs and PAEs and in selected ion monitoring (SIM) mode for OCPs. The electron ionization was $70 \mathrm{eV}$.

\section{Quality controls}

All data were subject to strict quality control procedures, including the analysis of blanks and spiked samples. The limit of detection (LOD) for each compound, estimated as three times response of signal-to-noise of 3:1 in blank sample, was $0.004-0.075 \mathrm{ng} \mathrm{g}^{-1}$ for OCPs, 0.013-0.220 $\mathrm{g} \mathrm{g} \mathrm{g}^{-1}$ for PAEs, $0.002-0.042 \mu \mathrm{g} \mathrm{g}^{-1}$ for PAHs and $0.003-0.022 \mu \mathrm{g} \mathrm{g}^{-1}$ for alkanes, respectively. The average recoveries $(n=5)$ were 94 $117 \%$ for OCPs, $75-129 \%$ for PAEs, $103-110 \%$ for PAHs and $82-105 \%$ for $n$-alkanes with relative standard deviations less than $14 \%$.

In addition, surrogates of 2,4,5,6-tetrachloro- $m$-xylene and 2-flurobiphenyl were added before extraction to compensate for the losses of OCPs and PAHs, respectively.

\section{Results and discussion}

This study reports on the results obtained from a survey of greenhouse soils from Beijing suburbs for the levels of several important organic contaminants (Table 1). The discussion will focus on HCHs, DDTs, EPA-PAHs and PAEs separately as follows:

\section{HCHs}

Concentrations of $\mathrm{HCHs}(\alpha-, \beta-, \gamma-$ and $\delta-\mathrm{HCH})$ ranged from 11.64 to $29.80 \mathrm{ng} \mathrm{g}^{-1}$ with a mean value of $15.77 \mathrm{ng} \mathrm{g}^{-1}$. Four isomers were detectable in every sample and spatial variations were observed ( $\mathrm{RSD}=36 \%$ ). It is difficult to assess the temporal variation of pollution in greenhouse soil from Beijing suburbs because of the lack of a previous study. In comparison to other areas, the $\mathrm{HCHs}$ level in this survey is lower than that

Table 1 Concentrations of organic pollutants in greenhouse soils from Beijing suburbs ( $\mathrm{ng} \mathrm{g}^{-1}$ for OCPs; $\mu \mathrm{g} \mathrm{g}^{-1}$ for PAHs and PAEs)

\begin{tabular}{|c|c|c|c|c|}
\hline & Abbreviation & Range & Mean & $\mathrm{SD}^{a}$ \\
\hline$\alpha-\mathrm{HCH}$ & & $0.40-2.58$ & 1.76 & 0.85 \\
\hline$\beta-\mathrm{HCH}$ & & $5.61-28.42$ & 11.92 & 7.35 \\
\hline$\gamma-\mathrm{HCH}$ & & $0.44-5.20$ & 1.53 & 1.61 \\
\hline$\delta-\mathrm{HCH}$ & & $0.12-1.51$ & 0.56 & 0.42 \\
\hline$p, p^{\prime}-\mathrm{DDE}$ & & $9.62-69.68$ & 39.72 & 21.41 \\
\hline$p, p^{\prime}$-DDD & & $0.61-4.68$ & 2.68 & 1.61 \\
\hline$o, p^{\prime}$-DDT & & $0.30-24.10$ & 8.39 & 8.86 \\
\hline$p, p^{\prime}-\mathrm{DDT}$ & & $5.41-24.57$ & 13.66 & 7.01 \\
\hline$\Sigma$ HCHs & & $11.64-29.80$ & 15.77 & 6.00 \\
\hline ¿DDTs & & $18.04-101.33$ & 64.44 & 30.36 \\
\hline Naphthalene & $\mathrm{Na}$ & $<0.04-0.06$ & 0.03 & 0.03 \\
\hline Acenaphthylene & $\mathrm{Ac}$ & $<0.01-0.05$ & 0.01 & 0.02 \\
\hline Acenaphthene & Ace & $0.01-0.03$ & 0.02 & 0.01 \\
\hline Fluorene & $\mathrm{Fl}$ & $0.02-0.07$ & 0.04 & 0.01 \\
\hline Phenanthrene & $\mathrm{Ph}$ & $0.14-0.43$ & 0.25 & 0.11 \\
\hline Anthracene & An & $0.03-0.08$ & 0.05 & 0.02 \\
\hline Fluoranthene & Flu & $0.17-0.86$ & 0.43 & 0.22 \\
\hline Pyrene & Pyr & $0.17-0.69$ & 0.35 & 0.16 \\
\hline Benz $[a]$ anthracene & $\mathrm{B}(\mathrm{a}) \mathrm{A}$ & $0.08-0.51$ & 0.23 & 0.13 \\
\hline Chryse & Chy & $0.13-0.67$ & 0.30 & 0.17 \\
\hline Benzo $[b]$ fluoranthene & $\mathrm{B}(\mathrm{b}) \mathrm{F}$ & $0.15-0.87$ & 0.38 & 0.24 \\
\hline Benzo $[k]$ fluoranthene & $\mathrm{B}(\mathrm{k}) \mathrm{F}$ & $0.14-0.83$ & 0.34 & 0.24 \\
\hline Benzo[e]pyrene & $\mathrm{B}(\mathrm{e}) \mathrm{P}$ & $0.15-0.85$ & 0.38 & 0.24 \\
\hline Benzo $[a]$ pyrene & $\mathrm{B}(\mathrm{a}) \mathrm{P}$ & $0.13-0.74$ & 0.30 & 0.20 \\
\hline Indeno $[1,2,3-c d]$ pyrene & InP & $0.10-0.70$ & 0.25 & 0.20 \\
\hline Dibenz $[a, h]$ anthracene & $\mathrm{DB}(\mathrm{ah}) \mathrm{A}$ & $0.01-0.28$ & 0.13 & 0.11 \\
\hline Benzo[g,h,i]perylene & B(ghi)P & $0.02-1.19$ & 0.40 & 0.37 \\
\hline$\Sigma$ EPA-PAHs & & $1.92-7.84$ & 3.51 & 1.97 \\
\hline Dimethyl phthalate & DMP & $<0.01-0.02$ & $<0.01$ & 0.01 \\
\hline Diethyl phthalate & DEP & $<0.01-0.05$ & $<0.01$ & 0.02 \\
\hline di-iso-butyl phthalate & DIBP & $0.31-0.94$ & 0.60 & 0.21 \\
\hline di-n-butyl phthalate & DnBP & $0.34-1.66$ & 1.14 & 0.32 \\
\hline di-(2-ethylhexyl) phthalate & DEHP & $0.22-0.74$ & 0.47 & 0.17 \\
\hline di-n-octyl phthalate & DnOP & $<0.09$ & $<0.09$ & 0.02 \\
\hline ¿PAEs & & $1.34-3.15$ & 2.21 & 0.58 \\
\hline
\end{tabular}


in rural areas of Jianghan plain in China $\left(455 \mathrm{ng} \mathrm{g}^{-1}\right)^{19}$ but higher than those detected in the USA, ${ }^{20}$ Germany, ${ }^{21}$ and some other European countries such as Belgium, Italy and Greece $\left(0.4-0.9 \mathrm{ng} \mathrm{g}^{-1}\right) .^{22}$

As for the composition patterns (Fig. 1), $\beta-\mathrm{HCH}$ is the major contributing compound of total $\mathrm{HCHs}$ studied, accounting for about $44-95 \%$. High $\beta$-isomer amount means an old source. This may attribute to the fact that $\beta-\mathrm{HCH}$ is the most stable and the most difficult isomer to degrade further in the environment. ${ }^{23}$ Ratio of $\alpha-\gamma-\mathrm{HCH}$ could provide information about the application, which is $4.3-5.0$ for industrial $\mathrm{HCHs}$ and nearly zero for lindane. ${ }^{24}$ In the current study, the ratio varied from 0.27 to 3.97 , which suggests potential applications of two HCHs in the greenhouse before.

\section{DDTs}

Concentrations of DDTs ( $p, p^{\prime}$-DDE, $p, p^{\prime}$-DDD, $o, p^{\prime}$-DDT and $p, p^{\prime}$ - DDT) ranged from 18.04 to $101.33 \mathrm{ng} \mathrm{g}^{-1}$ with a mean of $64.44 \mathrm{ng} \mathrm{g}^{-1}$. Four relative components were found in every sample and spatial variations were observed $(\mathrm{RSD}=47 \%)$. The level is lower than those in rural areas of the Jianghan plain (205 ng g $\left.{ }^{-1}\right),{ }^{19}$ in agricultural soils in British Columbia, Canada (194-763 $\mathrm{ng} \mathrm{g}^{-1}$ in silt loam soils; $2984-7162 \mathrm{ng} \mathrm{g}^{-1}$ in much soils $)^{25}$ and in Kanpur of India $\left(250 \mathrm{ng} \mathrm{g}^{-1}\right) .{ }^{26}$ However, the result in this survey is higher than those detected in the USA, ${ }^{20}$ Germany ${ }^{21}$ and some other European countries (6.7$\left.24.1 \mathrm{ng} \mathrm{g}^{-1}\right)$. $^{22}$

In soil, $p, p^{\prime}$-DDT is microbially transformed into the more stable metabolites of DDE and dichlorodiphenyldichloroethane (DDD). Ratio of the metabolites DDE and DDD to parent DDT could be used to qualitatively judge the age of DDTs residues. ${ }^{27}$ In this study, the ratio was $1.62-7.80$, suggesting that most of the parent DDT had been transformed into its metabolites.

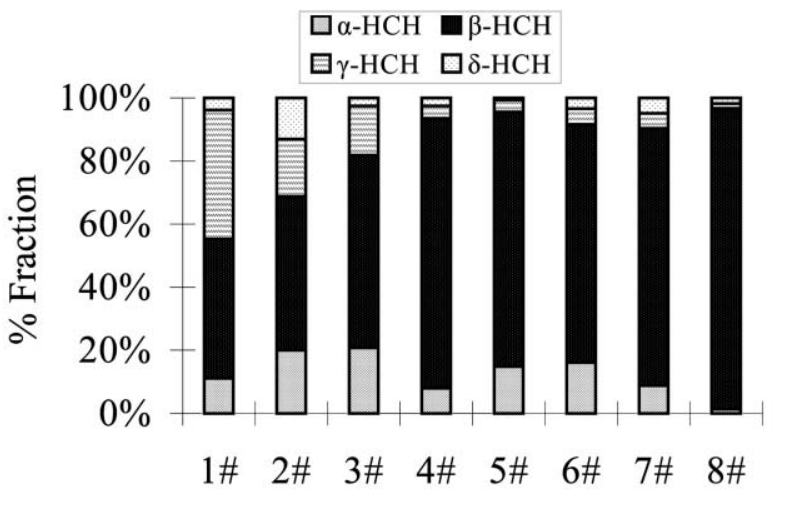

\section{Sample sites}

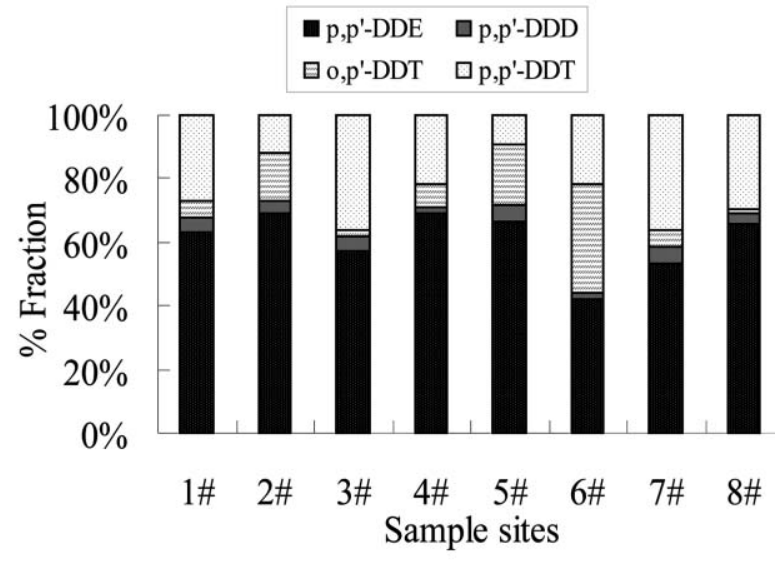

Fig. 1 Distribution of HCHs and DDTs in greenhouse soils from Beijing suburbs.
According to the guidelines of Chinese environmental quality standard for soils (GB15618-1995), in order to ensure the safe agricultural production and prevent food hazard to human health the maximum allowable concentration in soil should be less than $500 \mathrm{ng} \mathrm{g}^{-1}$ for both DDTs and HCHs. The levels of $\mathrm{HCHs}$ and DDTs here we found in greenhouse soil from Beijing suburbs are significantly below the guideline value. This may be attributed to the banned usage of industrial $\mathrm{HCHs}$ and DDTs in China for nearly 30 years. However, the half-life of $p, p^{\prime}$-DDT in soil is longer than 15 years ${ }^{28}$ and DDT together with its metabolites may act as endocrine disruptors, ${ }^{29}$ then it is necessary to monitor the status of DDTs in the region continuously.

\section{PAHs}

In the collected samples, total concentrations of the EPAPAHs at each site ranged from 1.92 to $7.84 \mu \mathrm{g} \mathrm{g}^{-1}$ with a mean value of $3.51 \mu \mathrm{g} \mathrm{g}^{-1} \mathrm{~B}(\mathrm{a}) \mathrm{P}$, one more important representative toxic PAH, was $0.13-0.74 \mu \mathrm{g} \mathrm{g}^{-1}$ with a mean value of $0.30 \mu \mathrm{g} \mathrm{g}^{-1}$, which is higher than that in an industrial or commercial area in Tokyo in Japan ${ }^{30}$ and in the city of Chiang-Mai in Thailand. ${ }^{31}$ Menzie et al. ${ }^{32}$ reviewed PAHs concentrations in the environment and reported that median concentration of the sum of 9 PAHs (BaA, Chy, B(e)P, B(b)F, B(k)F, $\mathrm{B}(\mathrm{a}) \mathrm{P}, \mathrm{B}$ (ghi)P, InP and DB(ah)A) was $1.10 \mu \mathrm{g} \mathrm{g}^{-1}$ for urban areas and $0.07 \mu \mathrm{g} \mathrm{g}^{-1}$ for rural areas, respectively. The corresponding concentration in this study was $2.25 \mu \mathrm{g} \mathrm{g}^{-1}$, which is even higher than that for urban areas. China still has no quality standard of PAHs in soil. Results here are much higher than the target value set by the Dutch government for unpolluted soil $\left(0.02-0.05 \mu \mathrm{g} \mathrm{g}^{-1}\right.$ dry weight) and the levels of two samples even exceed the intervention value $\left(4 \mu \mathrm{g} \mathrm{g}^{-1}\right)$ set for soil sanitation. ${ }^{33}$

Distribution of PAHs in every sample is similar with each group having a similar contribution to the total PAHs studied as given in Fig. 2. The profile has a great importance from the point of view of potential health effects. The most abundant hydrocarbons residing in greenhouse soils in Beijing suburbs are centered on the 4-, 5- and 6-ring PAHs which are known to be carcinogenic. ${ }^{34}$ One plausible explanation is that once deposited in the soil, lower molecular weight PAHs have much higher fluxes by volatilization and condensation, so they tend to evaporate to air or leak into deep soil while higher molecular weight PAHs are relatively less easily losing and then the distribution pattern of PAHs in soil would shift to higher weight PAHs. The other factor effecting the profiles of PAHs in soil may be the different sources. To identify the sources of PAHs, comparison of ratios of selected individual PAHs to $\mathrm{B}(\mathrm{e}) \mathrm{P}$ in the soil samples with those reported for the emission of different fossil fuels in literature ${ }^{35}$ may give some valuable hints

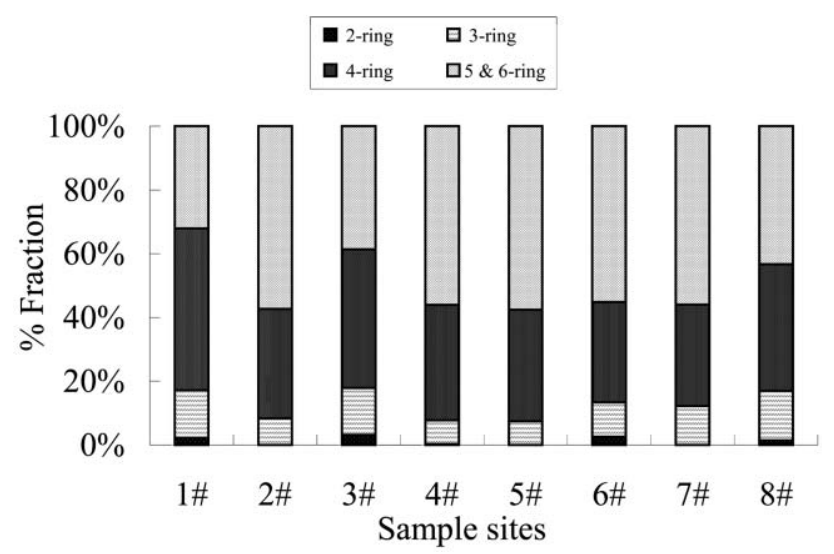

Fig. 2 Distribution of several classified PAHs in greenhouse soils from Beijing suburbs. 
(Table 2). Obviously, the ratios of Flu/B(e)P and $\mathrm{Py} / \mathrm{B}(\mathrm{e}) \mathrm{P}$ in greenhouse soils are far lower than those reported for any specific fossil fuels. In contrast, the ratios of higher molecular weight PAHs to $\mathrm{B}(\mathrm{e}) \mathrm{P}$ are in the range produced by burning of fossil fuels. Similar results were reported in soils of the tropical metropolis Bangkok. ${ }^{36}$ The result suggests that combustion of diesel and petrol is the major source of PAHs in the greenhouse soil. One typical total ion chromatogram is illustrated in Fig. 3 (see Table 1 for abbreviations). It seems that unsubstituted PAHs are the most abundant components, which also suggests combustion or pyrolysis process is dominant for the PAHs in this study. ${ }^{37}$ Furthermore, B(ghi)P is a known marker of traffic exhausts $^{38}$ with an average of $11 \%$ of the total PAHs concentrations in this study, which further reflects the important effect of the traffic on PAHs in Beijing suburban greenhouse soil.

In order to trace the natural or anthropogenic source of hydrocarbon, analysis of n-alkanes (from $\mathrm{C} 13$ to $\mathrm{C} 35$ ) was also performed. Every gas chromatogram shows an envelope of an unresolved complex mixture (UCM), which is characteristic of petroleum residues. ${ }^{39}$ However, carbon preference index (CPI), one important characteristic to reflect the relative contributions, is higher in greenhouse soils (2.1-3.9) than that commonly attributed to petroleum inputs $(\mathrm{CPI} \approx 1)^{40}$ and furthermore, the observed maximum carbon number in each sample was $\mathrm{C} 27$ and $\mathrm{C} 29$, which also suggests a terrestrial

Table 2 Ratios of PAHs to $\mathrm{B}(\mathrm{e}) \mathrm{P}$ in the Beijing suburban greenhouse soils and in the emissions of specific fuels $\mathrm{s}^{35}$

\begin{tabular}{|c|c|c|c|c|c|}
\hline & Flu & Py & Chy & $\mathrm{B}(\mathrm{bk}) \mathrm{F}^{a}$ & $\mathrm{~B}(\mathrm{a}) \mathrm{P}$ \\
\hline Lignite & 8 & 5 & 3 & 4 & 1.7 \\
\hline Hard coal & 7 & 6.5 & 2.2 & 3 & 1 \\
\hline Diesel & 7 & 8 & 1 & 2 & 0.5 \\
\hline Petrol & 20 & 35 & 3 & 1 & 1 \\
\hline Oil & 80 & 25 & 30 & 4 & 0.2 \\
\hline \multicolumn{6}{|l|}{ This study } \\
\hline Range & $0.93-2.25$ & $0.71-1.79$ & $0.58-1.23$ & $1.42-2.36$ & $0.57-1.01$ \\
\hline Average & 1.26 & 1.07 & 0.87 & 1.94 & 0.80 \\
\hline $\begin{array}{l}\text { Standard } \\
\text { deviation }\end{array}$ & 0.51 & 0.40 & 0.22 & 0.33 & 0.14 \\
\hline${ }^{a} \mathrm{~B}(\mathrm{~b}) \mathrm{F}$ and & $3(\mathrm{k}) \mathrm{F}$. & & & & \\
\hline
\end{tabular}

input. Therefore, the hydrocarbon pollution may be controlled by both plant and petroleum in the studied areas.

\section{Phthalate esters}

Six phthalates including DMP, DEP, DIBP, DnBP, DEHP and DnOP were detected. The total concentrations of phthalate esters in the greenhouses varied from 1.34 to $3.15 \mu \mathrm{g} \mathrm{g}^{-1}$. Such results are similar to those found in the city of Jinan ${ }^{41}$ and Shenyang. ${ }^{42}$ The low residues of phthalate esters in the greenhouse soils from Beijing suburbs would not result in harmful effects on vegetables as reported. ${ }^{8}$ One of the selected ion monitoring (SIM) chromatograms is presented in Fig. 4. The peaks were determined by selected ion $\mathrm{m} / \mathrm{z} 149$, which was commonly observed in many phthalates (except for DMP, 163 and 194). ${ }^{43}$ DIBP, DnBP and DEHP are the most frequently identified compounds in every sample, accounting for more than $97 \%$ of the total phthalates studied. Little data about DIBP in soil has been previously reported, while the compound was in all of the greenhouse samples $\left(0.24-0.94 \mu \mathrm{g} \mathrm{g}^{-1}\right)$, amounting to about $18-35 \%$. The trend of high DIBP, DnBP and DEHP values in soil is consistent with their high production. ${ }^{8}$ Such phthalate esters distribution is similar to the previous survey about phthalate esters in the greenhouse atmosphere. $^{44}$

\section{Conclusions}

The study has provided the first set of data on the levels of organic compounds including HCHs, DDTs, PAHs and PAEs in the greenhouse soils from Beijing suburbs. It extends our understanding of the current organic contamination status in the north of China. Concentrations of OCPs at all sites did not exceed the Chinese guideline values for soil. For PAHs, levels of two sites exceeded the intervention value set by the Dutch government for soil sanitation and the profile pointed out the necessity to adopt a more efficient and stricter strategy to control the exhausts of vehicles. Further work is needed, through regular sampling of soil and vegetables growing in greenhouses, to determine the bioaccumulation of organic pollutants in the food chain and then to assess the risks to human health.

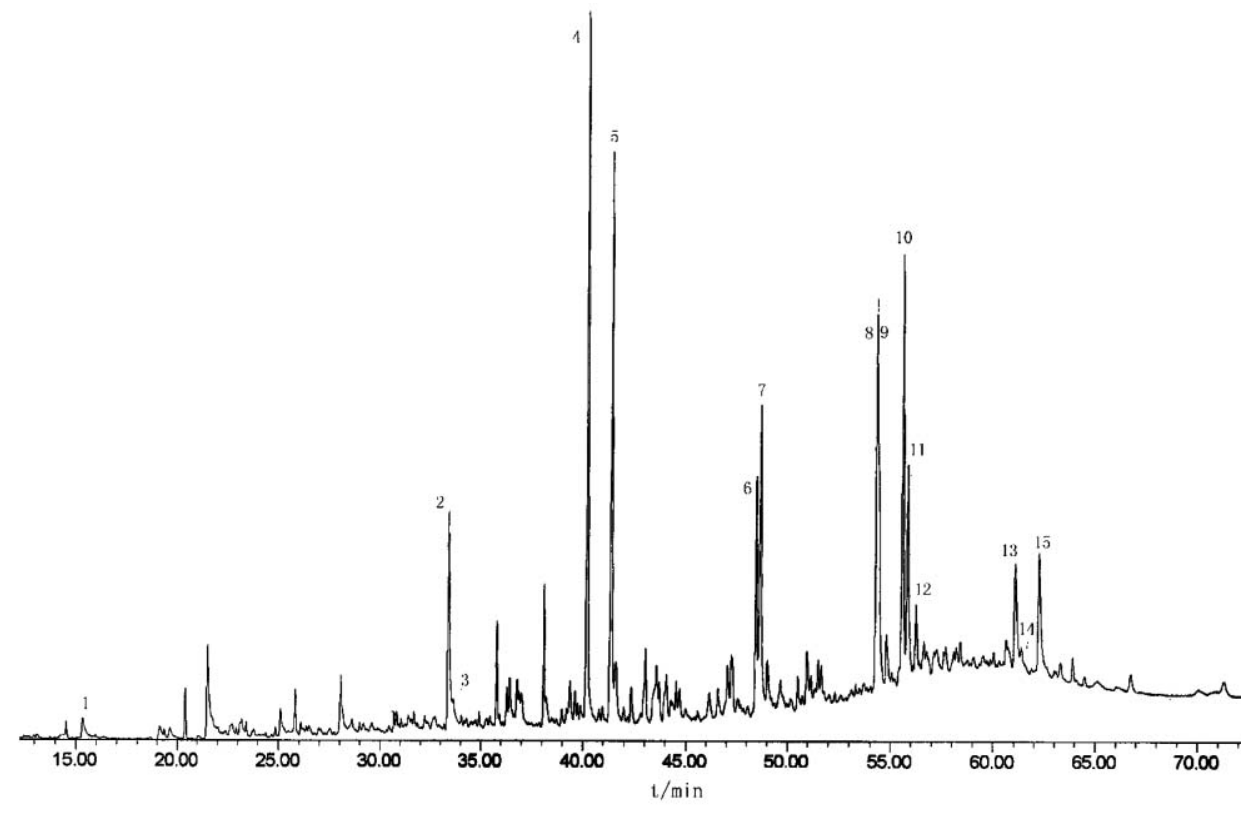

Fig. 3 One typical total ion chromatogram of PAHs in greenhouse soil. Peak numbers correspond to: (1) Na, (2) Ph, (3) An, (4) Flu (5) Pyr, (6) B(a)A (7) Chy, (8) B(b)F, (9) B(k)F, (10) B(e)P, (11) B(a)P, (12) Perylene, (13) InP, (14) DB(ah)A and (15) B(ghi)P. 


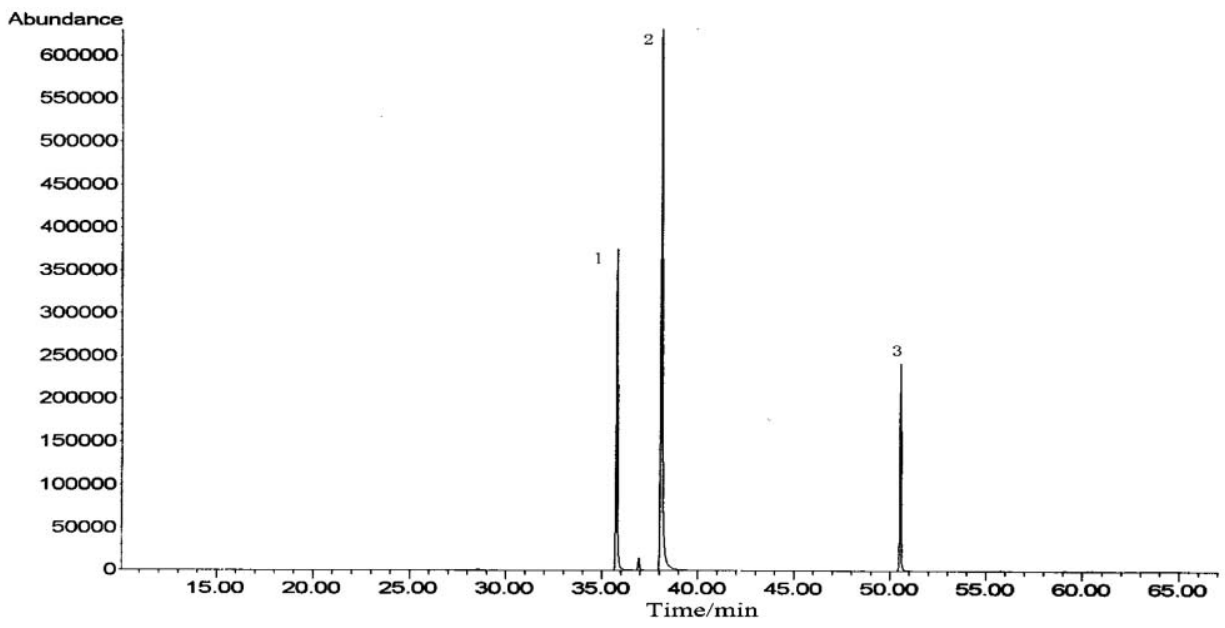

Fig. 4 One typical GC-MS selected ion monitoring (SIM) chromatogram of phthalate esters in greenhouse soil. Peak numbers correspond to: (1) DIBP, (2) DnBP and (3) DEHP.

\section{Acknowledgements}

We acknowledge financial support of this work by Major State Basic Research Program of China (No.G1999045707) and KIP of CAS (RCEES 9902, 9906). We also thank Agilent Technologies Co. Ltd (China) for GC-MS analysis.

\section{References}

1 K. L. Willett, E. M. Ulrich and R. A. Hites, Environ. Sci. Technol., 1998, 32, 2197.

2 S. Ghoshal, W. J. Weber, A. M. Rummel, J. E. Trosko and B. L. Upham, Environ. Sci. Technol., 1999, 33, 1044.

3 G. Yu, J. Huang and P. Y. Zhang, Environ. Protect., 2001, 4, 37 (in Chinese).

4 W. Z. Wu, K-W Schramm, B. Henkelmann, Y. Xu, A. Yediler and A. Kettrup, Chemosphere, 1997, 34, 191

5 Y. F. Li, Sci. Total Environ., 1999, 232, 121.

6 N. R. Khalili, P. A. Scheff and T. M. Holsen, Atmos. Environ., 1995, 29, 533.

7 P. Boffetta, N. Jourenkova and P. Gustavsson, Cancer Causes Control, 1997, 8, 444

8 C. A. Staples, D. R. Peterson, T. F. Parterton and W. J. Adams, Chemosphere, 1997, 25, 667.

9 E. Mylecreest, R. C. Cattley and P. M. D. Foster, Toxicol. Sci., 1998, 43, 47.

10 M. Ema, E. Miyawake and K. Kawashima, Reprod. Toxicol., 2000, 14, 13.

11 W. J. Kozumbo, R. Kroll and R. J. Rubin, Environ. Health Perspect., 1982, 45, 103.

12 A. Finizio, T. F. Bidleman and S. Y. Szeto, Chemosphere, 1998, 36, 345 .

13 D. T. Waite, R. Grover, N. D. Westtcott, H. Sommerstad and L. Kerr, Environ. Toxicol. Chem., 1992, 11, 741.

14 A. P. Schwab and D. L. Allan, Environ. Sci. Technol., 1995, 29, 551.

15 H. Z. Liu, H. J. Chen and X. Q. Wang, J. Hygiene Res., 1995, 24, 356 (in Chinese)

16 H. F. Yu, X. D. Zhao, X. M. Zhang, Z. Q. Zhu and J. L. Liu, J. Hygiene Res., 2001, 18, 352 (in Chinese).

17 I. Colon, D. Caro, C. J. Bourdony and O. Rosario, Environ. Health Perspect., 2000, 108, 895.

18 P. J. Boogaard and N. J. van Sittert, Sci. Total Environ., 1995, 163, 203.

19 J. Wang, J. B. Yang, Y. Z. Chen and L. W. Cai, Rural Ecoenvironment, 1998, 14, 53 (in Chinese).
20 T. Harner, J. L. Wideman, L. M. M. Jantunen, T. F. Bidleman and W. J. Parkhurst, Environ. Pollut., 1999, 106, 323.

21 M. Manz, K.-D. Wenzel, U. Dietze and G. Schüürmann, Sci. Total Environ., 2001, 277, 187.

22 A. Covaci, P. Manirakiza and P. Schepens, Bull. Environ. Contam. Toxicol., 2002, 68, 97.

23 D. Dannenberger, Mar. Pollut. Bull., 1996, 32, 772

24 B. Strandberg, C. Bandh, B. V. Bavel, P. A. Bergqvist, D. Broman, R. Ishaq, C. Naf and C. Rappe, Chemosphere, 2000, 40, 1205.

25 S. Y. Szeto and P. M. Price, J. Agric. Food Chem., 1991, 39, 1679.

26 R. Sanghi and K. S. Sasi, Bull. Environ. Contam. Toxicol., 2001, 67, 446.

27 T. Harner, J. L. Wideman, L. M. M. Jantunen, T. F. Bidlenam and M. J. Parkhurst, Environ. Pollut., 1999, 106, 323.

28 J. M. Aislabie, N. K. Richards and H. L. Boul, J. Agric. Res., 1997, 40, 269.

29 M. P. Longnecker, W. J. Rogan and G. Lucier, Annu. Rev. Public Health, 1997, 18, 211.

30 H. Matsushita, Y. Kato and Y. Hisamatsu, J. Jpn. Soc. Air Pollut., 1980, 15, 348 .

31 T. Amagai, Y. Takahashi, H. Matsushita, D. Morknoy, P. Sukasem and M. Tabucanon, Environ. Int., 1999, 25, 563.

32 C. A. Menzie, B. B. Potocki and J. Santodonato, Environ. Sci. Technol., 1992, 26, 1278.

33 T. C. Van Brummelen, R. A. Verweij, S. A. Wedzinga and C. A. M. Van Gestel, Chemosphere, 1996, 32, 293.

34 R. M. Kamens, G. Zhishi, J. N. Flulcher and D. A. Bell, Environ. Sci. Technol., 1988, 22, 103.

35 J. Jacob, G. Grimmer and A. Hildebrandt, Sci. Total Environ., 1993, 139(140), 307.

36 W. Wilcke, S. Müller, N. Kanchanakool, C. Niamskul and W. Zech, Geoderma, 1999, 91, 297.

37 W. W. Youngblood and M. Blumer, Geochim. Cosmochim. Acta, 1975, 39, 1303.

38 S. O. Baek, R. A. Field, M. E. Goldstone, P. W. Kirk, J. N. Lester and R. Perry, Water Air Soil Pollut., 1991, 60, 279.

39 P. M. Fraser, G. R. Cass, B. R. T. Simoneit and R. A. Rasmussen, Environ. Sci. Technol., 1997, 31, 2356.

40 E. G. Stephanou, Atmos. Environ., 1992, 26A, 2821.

41 X. K. Wang, W. L. Guo, P. R. Meng and J. A. Gan, Chinese Chem. Lett., 2002, 13, 557.

42 G. C. Tang, Y. Q. Cai and S. L. Wang, Rural Eco-Environment, 1993, 3, 36 (in Chinese).

43 D. B. Giuseppa, S. Marcello, P. Mariacristina, S. Francesco and D. Giacomo, J. Agric. Food Chem., 1999, 47, 1009.

44 B. Tienpont, F. David, P. Sandra and F. Vanwalleghem, J. Microcol. Sep., 2000, 12, 194. 